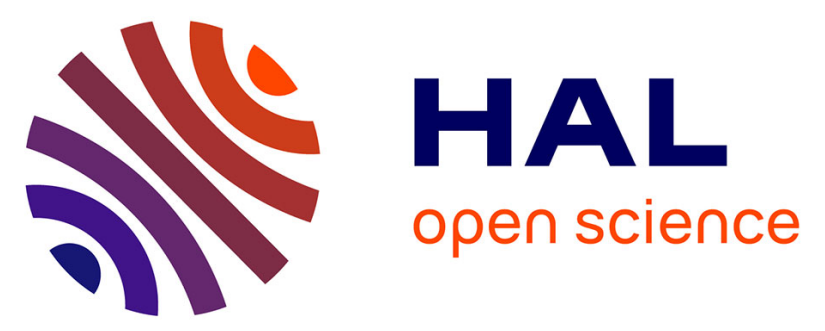

\title{
Quality of life in children participating in a non-selective INR self-monitoring VKA-education programme
}

\author{
Pascal Amedro, Fanny Bajolle, Héléna Bertet, Radhia Cheurfi, Dominique
} Lasne, Erika Nogué, Pascal Auquier, Marie-Christine Picot, Damien Bonnet

\section{- To cite this version:}

Pascal Amedro, Fanny Bajolle, Héléna Bertet, Radhia Cheurfi, Dominique Lasne, et al.. Quality of life in children participating in a non-selective INR self-monitoring VKA-education programme. Archives of cardiovascular diseases, 2018, 111 (3), pp.180 - 188. 10.1016/j.acvd.2017.05.013 . hal-01786609

\section{HAL Id: hal-01786609 \\ https://hal.umontpellier.fr/hal-01786609}

Submitted on 17 Apr 2020

HAL is a multi-disciplinary open access archive for the deposit and dissemination of scientific research documents, whether they are published or not. The documents may come from teaching and research institutions in France or abroad, or from public or private research centers.
L'archive ouverte pluridisciplinaire HAL, est destinée au dépôt et à la diffusion de documents scientifiques de niveau recherche, publiés ou non, émanant des établissements d'enseignement et de recherche français ou étrangers, des laboratoires publics ou privés. 


\title{
Quality of life in children participating in a non-selective INR self-monitoring VKA-education programme
}

\section{Qualité de vie des enfants sous AVK participant à un programme d'éducation} thérapeutique non sélectif à l'auto-mesure de l'INR

\author{
Pascal Amedro ${ }^{\mathrm{a}, \mathrm{b}, *}$, Fanny Bajolle ${ }^{\mathrm{c}}$, Helena Bertet ${ }^{\mathrm{d}}$, \\ Radhia Cheurfi ${ }^{c}$, Dominique Lasne ${ }^{e}$, Erika Nogue ${ }^{e}$, \\ Pascal Auquier ${ }^{\mathrm{b}}$, Marie-Christine Picot $^{\mathrm{d}}$, \\ Damien Bonnet ${ }^{c}$
}

a Pediatric and Congenital Cardiology Department, M3C Regional Reference Center, University Hospital, Physiology and Experimental Biology of Heart and Muscles Laboratory, PHYMEDEXP, UMR CNRS 9214-Inserm U1046, University of Montpellier, Montpellier, France

${ }^{b}$ Self-perceived Health Assessment Research Unit, EA3279, Public Health Department, Aix-Marseille University, Marseille, France

c Pediatric Cardiology Department, AP-HP, Necker-Enfants malades, M3C National Reference Center, Paris Descartes University, Sorbonne Paris Cité, Paris, France

${ }^{\mathrm{d}}$ Epidemiology Department, University Hospital, Clinical Investigation Center, Inserm-CIC 1411, Montpellier, France

e Hematology Laboratory, AP-HP, Necker-Enfants malades, Paris, France

\section{KEYWORDS}

Quality of life;

INR

\section{Summary}

Background. - The quality of life (QoL) of children receiving vitamin $\mathrm{K}$ antagonist (VKA) treatment has been scarcely studied.

Aim. - To assess QoL of children, and its evolution, throughout our non-selective international normalized ratio (INR) self-monitoring education programme.

Abbreviations: CHD, congenital heart disease; M3C, French National Reference Center for Complex Congenital Heart Diseases; QoL, quality of life; VKA, vitamin K antagonist.

* Corresponding author. Pediatric and congenital cardiology department, Arnaud-De-Villeneuve University Hospital, 371, avenue du DoyenGiraud, 34295 Montpellier, France.

E-mail address: p-amedro@chu-montpellier.fr (P. Amedro). 
Vitamin $\mathrm{K}$ antagonist; Paediatrics;

Patient education
Methods. - Children and parents completed QoL questionnaires (Qualin, PedsQL) during education sessions. Scores were compared with those from controls.

Results. - A total of 111 children (mean \pm standard deviation age $8.7 \pm 5.4$ years) were included over a 3-year period. Indications for VKA treatment were congenital heart diseases (valve replacement [42.3\%], total cavopulmonary connection [29.7\%]), myocardiopathy (11.7\%), coronary aneurysm $(7.2 \%)$, venous/intracardiac thrombosis $(4.5 \%)$, pulmonary artery hypertension $(1.8 \%)$, arrhythmia $(0.9 \%)$ and extra-cardiac disease (1.8\%). Eighty children, 105 mothers and 74 fathers completed the QoL questionnaires. QoL was good among children aged $1-4$ years and moderately impaired in those aged between 5 and 18 years. There was no significant relationship between self-reported QoL and patient's sex, type of VKA, number of group sessions attended, disease duration or time of diagnosis (prenatal or postnatal). QoL scores were significantly lower among children with congenital heart diseases compared with other diseases. There were few differences in QoL between children under transient VKA treatment and those treated for life. Parental proxy QoL scoring correlated well with but was significantly lower than child self-assessments. QoL reported by mothers increased throughout the education programme, independently of any improvement of the health condition.

Conclusions. - This QoL study provides original data from a large cohort of children and their parents participating in a formalized INR self-monitoring education programme for VKA treatment.

\section{MOTS CLÉS \\ Qualité de vie ; INR ; Antivitamines K ; Pédiatrie ; Éducation thérapeutique du patient}

\begin{abstract}
Résumé
Contexte. - La qualité de vie ( $\mathrm{QdV})$ des enfants sous anti-vitamine $\mathrm{K}(\mathrm{AVK})$ a été très peu étudiée.

Objectif. - Nous avons souhaité mesurer la QdV des enfants sous AVK et son évolution au cours de notre programme d'éducation thérapeutique non sélectif sur l'auto-mesure de l'INR.

Méthodes. - Enfants et parents ont rempli des questionnaires de QdV génériques (Qualin, Ped$\mathrm{sQL})$ lors des séances d'éducation. Les scores ont été comparés aux témoins.
\end{abstract}

Résultats. - Cent onze enfants (âge moyen : $8,7 \pm 5,4$ ans) ont été inclus sur trois ans. Les indications d'AVK étaient: cardiopathies congénitales (remplacement valvulaire $(42,3 \%)$, dérivation cavopulmonaire totale $(29,7 \%)$, myocardiopathie $(11,7 \%)$, anévrisme coronarien $(7,2 \%)$, thrombose veineuse/intracardiaque $(4,5 \%)$, hypertension artérielle pulmonaire $(1,8 \%)$, arythmies $(0,9 \%)$ et maladies extracardiaques $(1,8 \%)$. Quatre-vingt enfants, 105 mères et 74 pères ont rempli les questionnaires. La QdV était bonne chez les enfants âgés de 1 à 4 ans, modérément altérée entre 5 et 18 ans. Nous n'avons pas mis en évidence de relation significative entre automesure de la QdV et sexe du patient, type d'AVK, nombre de séances d'éducation, durée de la maladie et moment du diagnostic (prénatal ou postnatal). Les scores de QdV étaient significativement plus faibles chez les enfants atteints de cardiopathies congénitales comparativement aux autres maladies. Il y avait peu de différences de QdV entre les enfants sous traitement AVK transitoire et ceux traités à vie. Les scores de QdV mesurés par les pères et les mères étaient bien corrélés entre eux mais inférieurs aux auto-mesures des enfants. La QdV mesurée par les mères s'est améliorée au cours du programme d'éducation, indépendamment de toute amélioration de l'état de santé.

Conclusions. - À partir d'une importante cohorte d'enfants sous AVK, cette étude apporte des données originales sur la QdV au cours d'un programme d'éducation thérapeutique non sélectif sur l'auto-mesure de l'INR. 


\section{Background}

More consideration is now given to patient-related outcomes [1], especially in assessing the quality of life (QoL) of children with congenital heart diseases (CHD) [2]. QoL has been defined as the "overall life satisfaction" [3], but most clinical trials require a more operational definition and use health-related quality of life questionnaires [4].

Survival of children with more complex CHD have led to new burdens related to the need for long-term anticoagulation with vitamin $\mathrm{K}$ antagonist (VKA) treatment in a variety of conditions. The use of selective international normalized ratio (INR) self-monitoring using a self-measurement device at home has proven safe in children receiving VKA therapy [5-7]. Whereas most patients claim that they are comfortable with self-measurement devices, QoL has been scarcely evaluated in this population. QoL studies in adults have delivered contradictory findings [8-14]. Data from paediatric studies with small cohorts suggest QoL improvement during INR-self monitoring programmes $[15,16]$, but without any data from the child or their parents.

Our non-selective child-focused education programme appeared to be useful in maintaining efficacy, safety and compliance to anticoagulation and its monitoring [17]. Here, we aimed to assess the QoL of children included in our education programme in comparison with a control population. We also assessed QoL evolution throughout the education programme and compared the child's with the mother's and father's proxy evaluations.

\section{Methods}

This prospective cohort study was carried out in Necker M3C national reference centre, Paris, France, with a 3-year recruitment and observation period. Children aged 0 to 18 years who were receiving VKA treatment for any reason, prescribed for $>3$ months and using an INR self-monitoring device were eligible. All patients and/or parents participating in our INR self-monitoring education programme were invited to complete a generic QoL questionnaire during each education session.

\section{INR self-monitoring and VKA education programme}

As previously reported [17], our non-selective educational programme starts with an initial session divided into five parts: VKA theoretical training, self-measurement device practical training (CoaguChek XS), group session (game, discussion), administration of QoL questionnaires, and evaluation. Six months later, a reinforcement (i.e. support) session is organized. Participation in the support session is not mandatory, but is based on the family, child or physician's demand. The global clinical status of the child (stable, worse, better) was established by a paediatric cardiologist at the last session.

\section{Health-related QoL questionnaires}

Two generic paediatric QoL questionnaires were used: the Qualin questionnaire for infants $<2$ years of age [18] and the
PedsQL questionnaire for children aged between 2 and 18 years $[19,20]$. Both parents could participate and completed their proxy questionnaires separately. We used the following versions of the PedsQL, depending on the patient's age: proxy reports for children aged 2 to 4 years, and self and proxy reports for children aged $5-7,8-12$, and $13-18$ years. PedsQL self-reports were completed by the children under trained nurse supervising. All families were administered a questionnaire after the first session of the education programme, 6 months later, and, when applicable, if VKA was stopped before 6 months.

The Qualin questionnaire is a 34-item generic French QoL instrument designed for infants (aged $0-3$ years) and was completed by parents or caregivers. Each answer scores from -2 (totally false) to +2 (quite true). An item with a score $>1$ corresponds to favourable QoL. The psychometric properties are satisfactory (acceptability 90\%, Cronbach's alpha coefficient $>0.75$, correlations between two raters $>0.50$, good construct validity) [18].

The PedsQL generic QoL questionnaire has four multidimensional scales: physical functioning ( 8 items), emotional functioning ( 5 items), social functioning ( 5 items), and school functioning ( 5 items). The three summary scores are total scale score (23 items), physical health summary score ( 8 items), and psychosocial health summary score (15 items). Each item uses a 5-point Likert scale from 0 (never) to 4 (almost always). Items are reversed scored and linearly transformed to a $0-100$ scale, higher scores indicating a better QoL. Psychometric properties showed reliability, validity and responsiveness to clinical change over time [19]. The translation and cultural adaptation into French was performed by MAPI Research Institute (www. mapi-trust.org) following the international guidelines [21]. The psychometric properties of the French version of the PedsQL appeared to be acceptable [22].

\section{Control population}

The normal values from the literature were used for healthy children aged $<8$ years $[18,19,23]$. For children aged from 8 to 18 years, we used the data from our own recently reported comparative QoL study: 180 families of children aged 8 to 18 years were recruited in randomly selected schools and completed self and proxy QoL questionnaires [2].

\section{Formal aspects}

This study complies with the declaration of Helsinki. It was approved by our regional Ethics Committee (Île-deFrance III) and is registered on ClinicalTrials.gov (number NCT01202916). The Ministry of Education Regional Authority authorized schools' participation. Informed consent was obtained from all parents.

\section{Statistical analysis}

Patient characteristics are presented using mean and standard deviation (SD) for continuous variables and as frequencies and proportions for qualitative variables. Total QoL scores and subscore dimensions were calculated for each questionnaire. QoL scores were compared with the 
parametric Student's $t$-test when the distribution was Gaussian, and with the Mann-Whitney test otherwise, for the following variables: sex, pathology, time of diagnosis (prenatal or postnatal), type of VKA, duration of VKA prescription (life-long or transient), and type and number of therapeutic education sessions attended. Correlations between time since diagnosis and QoL scores were studied using Pearson's or Spearman's coefficient. Comparisons and correlations were performed independently for Qualin and PedsQL, for initial and final evaluations and for children, mothers and fathers. QoL scores were compared between self-reports, maternal reports and paternal reports, and between baseline and final evaluations, using paired Student's or Wilcoxon tests depending on the distribution. The Qualin and PedsQL internal reliability were evaluated with Cronbach $\alpha$ coefficient.

The two-sided significance level was 0.05 . SAS version 9 (SAS Institute, Cary, NC) was used.

\section{Results}

\section{Patient characteristics}

A total of 111 children participated in our INR selfmonitoring programme. No family refused to be enrolled in the QoL study. Data on the indications for VKA, types of VKA and education programme participation are detailed in Table 1. For the 111 children, 426 QoL questionnaires (25 Qualin, 401 PedsQL) were completed by 259 people ( 80 children, 105 mothers, 74 fathers) (Table 2).

\section{Qualin QoL scores}

Two parents of infants aged $<1$ year participated in the education programme and completed the Qualin questionnaire. The QoL global score was low $(-0.1 \pm 0.1)$ (vs a normal value of 0.9$)$.

Eleven mothers and 10 fathers of children aged $>1$ and $<2$ years participated in the education programme and completed the Qualin questionnaire. Parents' proxy QoL global scores were close to normal values: $1.1 \pm 0.2$ for mothers and $1.2 \pm 0.3$ for fathers (vs a normal value of 0.9 ) (Fig. $1 \mathrm{~A}$

Ine Qualin internal reliability was satisfactory, with a Cronbach coefficient of 0.89 for mothers, 0.93 for fathers and 0.91 globally.

\section{PedsQL QoL scores}

In all three subgroups of age (5-7, 8-12 and 13-18 years), children's self-reported QoL scores were significantly lower than controls globally and in all dimensions except school and physical dimensions in the group aged $5-7$ years and school and emotion dimensions in the group aged 13-18 years (Fig. 1B-D

In the group aged 2-4 years, mother-reported proxy scores were significantly lower than controls globally and in all dimensions except social, whereas father-reported proxy scores were not significantly different from controls (Fig. 2A). In the group aged 5-7 years, mother-reported scores were significantly lower than control scores in all
Table 1 Patient baseline characteristics.

\begin{tabular}{|c|c|}
\hline Variable & \\
\hline Age, years & $8.7(5.4)$ \\
\hline Male & $57(51.4)$ \\
\hline \multicolumn{2}{|l|}{ Pathology } \\
\hline Congenital heart disease & $80(72.0)$ \\
\hline Valve replacement & $47(42.3)$ \\
\hline Aortic valve & $13(11.7)$ \\
\hline Mitral valve & $33(29.7)$ \\
\hline Pulmonary valve & $1(0.9)$ \\
\hline Total cavopulmonary connection & $33(29.7)$ \\
\hline Myocardiopathy & $13(11.7)$ \\
\hline Coronary aneurysm & $8(7.2)$ \\
\hline Venous or intracardiac thrombosis & $5(4.5)$ \\
\hline Stroke & $2(1.8)$ \\
\hline Deep vein thrombosis & $1(0.9)$ \\
\hline Pulmonary embolism & $1(0.9)$ \\
\hline Right atrium thrombus & $1(0.9)$ \\
\hline Pulmonary artery hypertension & $2(1.8)$ \\
\hline Arrhythmia & $1(0.9)$ \\
\hline Extra-cardiac disease & $2(1.8)$ \\
\hline Antiphospholipid antibody syndrome & $1(0.9)$ \\
\hline Systemic lupus & $1(0.9)$ \\
\hline \multicolumn{2}{|l|}{ VKA } \\
\hline Warfarin & $78(70.3)$ \\
\hline Fluindione & $24(21.6)$ \\
\hline Acenocoumarol & $3(2.7)$ \\
\hline Use of several VKAs consecutively & $6(5.4)$ \\
\hline \multicolumn{2}{|l|}{ VKA educational program } \\
\hline \multicolumn{2}{|l|}{ Type of sessions } \\
\hline Initial session + support session & $75(67.6)$ \\
\hline Initial session only & $36(32.4)$ \\
\hline \multicolumn{2}{|l|}{ Number of sessions } \\
\hline 1 & $36(32.4)$ \\
\hline 2 & $74(66.7)$ \\
\hline 3 & $1(0.9)$ \\
\hline
\end{tabular}

Data are expressed as mean \pm standard deviation or number (\%). VKA: vitamin $\mathrm{K}$ antagonist.

dimensions whereas father-reported scores were significantly lower than controls in the school and psychosocial dimensions only (Fig. 2B). In the groups aged 8-12 and 13-18 years, parent-reported QoL scores were significantly lower than controls globally and in all dimensions except emotion for children aged 13-18 years (Fig. 2C and D

The PedsQL internal reliability was satisfactory, with a Cronbach coefficient of 0.91 . When the questionnaires completed by children, mothers and fathers were separated, internal reliability remained satisfactory, with Cronbach coefficients of $0.88,0.92$ and 0.92 , respectively.

\section{Factors associated with PedsQL scores}

PedsQL self-reported scores were not affected by sex, type of VKA, type of education sessions attended, duration of VKA prescription (life-long or transient treatment) or time of diagnosis (prenatal or postnatal), at both baseline and final 
Table 2 Number of quality-of-life questionnaires administered throughout the programme.

\begin{tabular}{|c|c|c|c|c|c|c|c|}
\hline & \multicolumn{3}{|l|}{ Baseline } & \multicolumn{3}{|l|}{ Final } & \multirow[t]{2}{*}{ Total } \\
\hline & Fathers & Mothers & Children & Fathers & Mothers & Children & \\
\hline Qualin (n) & 11 & 12 & 0 & 1 & 1 & 0 & 25 \\
\hline PedsQL $(n)$ & 63 & 93 & 80 & 39 & 67 & 59 & 401 \\
\hline Total $(n)$ & 74 & 105 & 80 & 40 & 68 & 59 & 426 \\
\hline
\end{tabular}

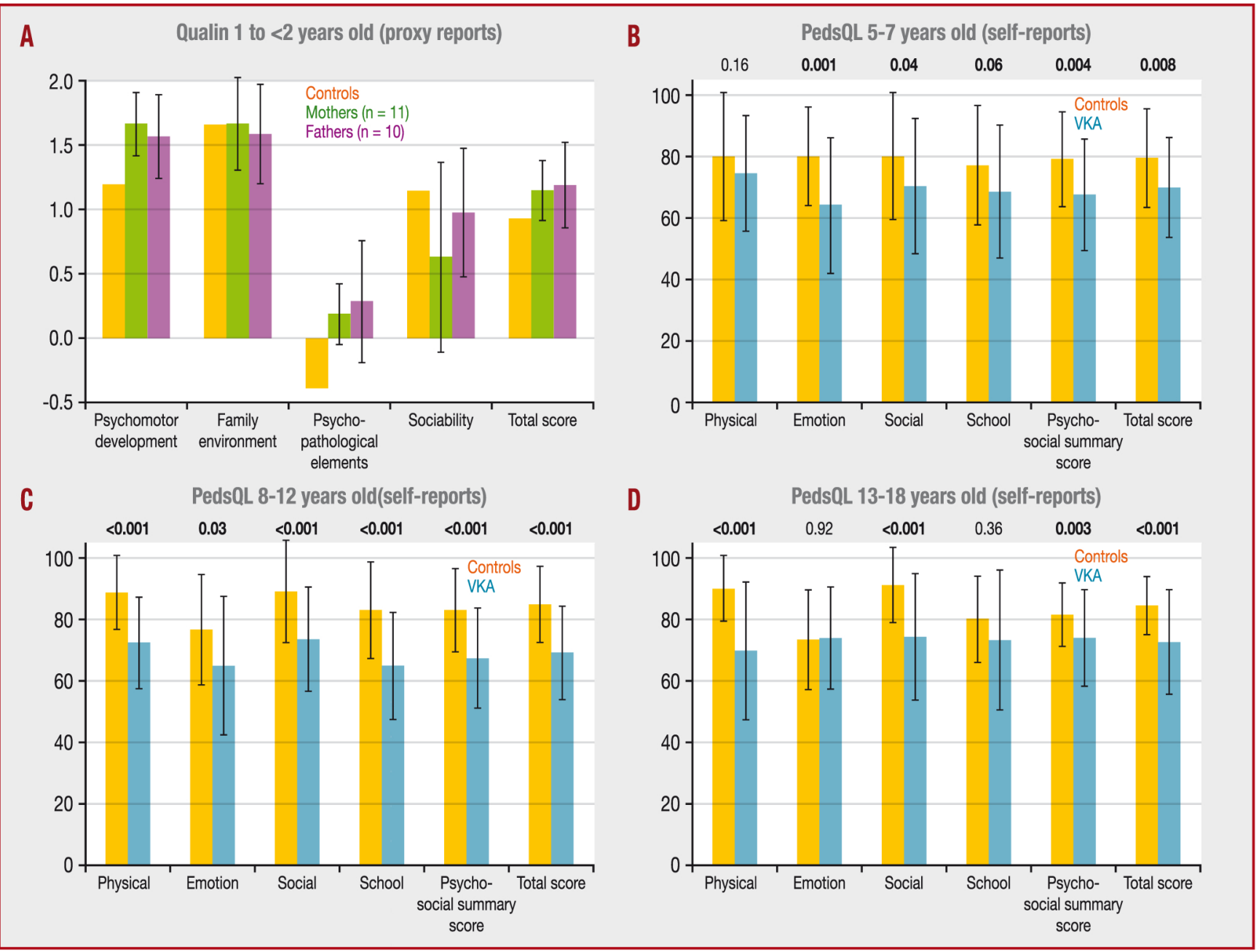

Figure 1. Qualin QoL scores and PedsQL self-reported scores. Mean values are represented by bars. Significance of the comparisons versus controls are indicate by the $P$-values above the bars.

evaluations. QoL evaluation by mothers and fathers was not impacted by sex or type and number of education sessions (data not shown).

At the final evaluation, mother-reported QoL scores were higher for children treated with warfarin versus fluindione in several dimensions: school $(79.9 \pm 15.4$ vs $67.1 \pm 24.2 ; P=0.02)$, physical $(80.0 \pm 17.5$ vs $65.1 \pm 24.3$; $P=0.03)$, social $(80.4 \pm 15.4$ vs $69.0 \pm 18.2 ; P=0.04)$, and total score $(77.1 \pm 14.4$ vs $66.7 \pm 19.5 ; P=0.03)$. At the final evaluation, mother-reported QoL scores were lower for children with prenatal versus post-natal diagnosis in the emotion (53.8 \pm 15.3 vs $71.6 \pm 20.9 ; P=0.005)$ and psychological $(64.5 \pm 12.1$ vs $74.9 \pm 17.0 ; P=0.04)$ dimensions. At baseline, the father-reported physical score was higher for children with long-life treatment than for those with transient treatment $(71.4 \pm 22.8$ vs $55.6 \pm 24.2 ; P=0.02)$. Disease duration was negatively correlated with several father-reported scores at the final evaluation: school $(r=-0.57 ; P<0.01)$, emotion $(r=-0.45 ; P<0.01)$, physical $(r=-0.60 ; P<0.001)$, psychological $(r=-0.57 ; P<0.001)$, social $(r=-0.55 ; P<0.001)$ and total score $(r=-0.62$; $P<0.001)$. Disease duration was negatively correlated with 


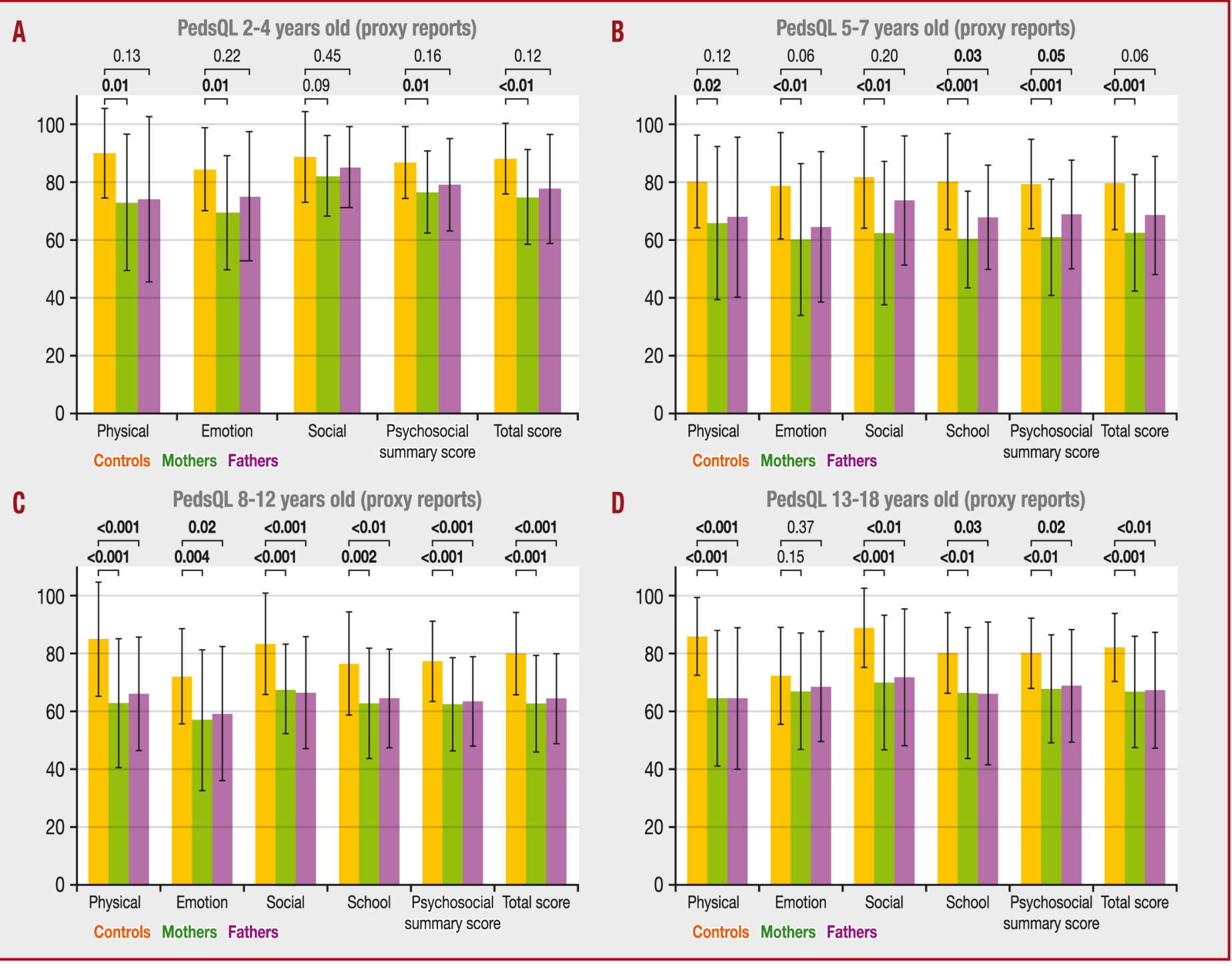

Figure 2. PedsQL parents' reported scores. Mean values are represented by bars. Significance of the comparisons versus controls are indicated by the $P$-values above the bars.

the mother-reported physical score at the final evaluation $(r=-0.23 ; P=0.05)$.

QoL was impaired in children with CHD (heart valve diseases and total cavopulmonary connections, $n=80$ ) compared to children with other diseases (Table 3). Almost all dimensions were affected in self, maternal and paternal proxy reports at baseline and in the final evaluations. The QoL of children receiving life-long VKA after valve replacement $(n=47)$ was not significantly different from that of other children for all dimensions and at each step of the programme.

\section{Evolution of PedsQL scores throughout the education programme}

Mothers' reported PedsQL scores increased significantly throughout the programme globally and in physical, school and psychosocial dimensions (Table 4). Self-reported and father-reported PedsQL scores did not vary significantly between initial and final sessions. Only a tendency toward increased scores was observed for self-reports in the school dimension and for paternal reports in school and physical dimensions.

No statistical link was found between the change in PedsQL scores throughout the programme and the evolution of the global clinical status of the child (stable, worse, better) evaluated by the paediatric cardiologist $(P>0.05$ in all dimensions).

\section{Comparison between child, maternal and paternal reports}

No difference between QoL scores was found when comparing pairs of maternal and paternal reports with the Qualin and PedsQL questionnaires (Table 5) administered at the same time, and for their first administration. Maternal reported PedsQL global scores were significantly lower than child self-reports, with all dimensions affected (Supplementary Table 4). Paternal reported PedsQL global scores were also lower than child self-reports, with only the physical dimension significantly affected Table 4). 
Table 3 PedsQL scores in children with CHD versus other diseases according to mother-, father- and self-reports at baseline and final evaluations.

\begin{tabular}{|c|c|c|c|c|c|c|c|c|c|}
\hline & \multicolumn{3}{|l|}{ Mother-report } & \multicolumn{3}{|c|}{ Father-report } & \multicolumn{3}{|l|}{ Self-report } \\
\hline & $\mathrm{CHD}$ & $\begin{array}{l}\text { Other } \\
\text { diseases }^{a}\end{array}$ & $P$ & $\mathrm{CHD}$ & $\begin{array}{l}\text { Other } \\
\text { diseases }^{a}\end{array}$ & $P$ & $\mathrm{CHD}$ & $\begin{array}{l}\text { Other } \\
\text { diseases }^{a}\end{array}$ & $P$ \\
\hline \multicolumn{10}{|l|}{ Baseline } \\
\hline School & $64.5 \pm 19.3$ & $71.0 \pm 25.9$ & 0.12 & $65.3 \pm 20.0$ & $80.7 \pm 14.7$ & 0.02 & $68.0 \pm 79.6$ & $79.6 \pm 27.8$ & 0.01 \\
\hline Emotion & $61.5 \pm 22.6$ & $70.8 \pm 23.0$ & 0.15 & $63.1 \pm 23.6$ & $78.3 \pm 16.0$ & 0.04 & $67.1 \pm 20.6$ & $77.3 \pm 17.0$ & 0.11 \\
\hline Physical & $64.9 \pm 23.2$ & $69.3 \pm 26.7$ & 0.46 & $65.7 \pm 23.8$ & $74.7 \pm 23.5$ & 0.25 & $70.8 \pm 18.5$ & $79.2 \pm 24.0$ & 0.07 \\
\hline Psychological & $64.5 \pm 17.4$ & $74.0 \pm 21.0$ & 0.03 & $65.9 \pm 17.7$ & $82.5 \pm 12.7$ & 0.004 & $68.5 \pm 16.0$ & $80.4 \pm 18.5$ & 0.007 \\
\hline Social & $67.3 \pm 21.1$ & $79.7 \pm 20.0$ & 0.03 & $68.2 \pm 20.1$ & $90.4 \pm 12.7$ & $<0.001$ & $71.1 \pm 20.0$ & $83.7 \pm 17.0$ & 0.03 \\
\hline Total & $64.7 \pm 17.8$ & $71.8 \pm 21.7$ & 0.13 & $66.1 \pm 18.6$ & $79.3 \pm 15.7$ & 0.03 & $69.3 \pm 15.1$ & $80.0 \pm 19.7$ & 0.01 \\
\hline \multicolumn{10}{|l|}{ Final } \\
\hline School & $72.9 \pm 19.4$ & $91.7 \pm 7.9$ & 0.005 & $69.4 \pm 17.9$ & $84.8 \pm 15.4$ & 0.03 & $72.8 \pm 17.9$ & $85.0 \pm 11.0$ & 0.07 \\
\hline Emotion & $65.02 \pm 20.7$ & $85.1 \pm 15.1$ & 0.003 & $66.7 \pm 20.8$ & $86.5 \pm 18.9$ & 0.02 & $69.9 \pm 20.5$ & $86.9 \pm 12.5$ & 0.02 \\
\hline Physical & $72.4 \pm 20.7$ & $90.0 \pm 13.4$ & 0.006 & $74.3 \pm 20.9$ & $87.8 \pm 21.7$ & 0.04 & $72.3 \pm 20.0$ & $85.9 \pm 12.3$ & 0.05 \\
\hline Psychological & $70.4 \pm 16.5$ & $87.2 \pm 7.5$ & 0.002 & $67.7 \pm 16.6$ & $88.2 \pm 16.4$ & 0.005 & $71.7 \pm 16.1$ & $85.6 \pm 8.3$ & 0.02 \\
\hline Social & $73.9 \pm 18.1$ & $86.0 \pm 10.5$ & 0.07 & $67.6 \pm 19.8$ & $91.5 \pm 18.4$ & $<0.001$ & $72.4 \pm 18.9$ & $85.0 \pm 13.4$ & 0.07 \\
\hline Total & $71.1 \pm 16.2$ & $88.03 \pm 8.3$ & 0.002 & $70.1 \pm 16.0$ & $88.1 \pm 18.1$ & 0.009 & $71.9 \pm 15.0$ & $85.7 \pm 8.7$ & 0.01 \\
\hline
\end{tabular}

Table 4 PedsQL scores: comparison between baseline and final evaluations for self- and parent-reports.

\begin{tabular}{lllr}
\hline Dimension & Baseline $^{\mathrm{a}}$ & Final $^{\mathrm{a}}$ & \multicolumn{1}{l}{$P$} \\
\hline Self-report & $n=59$ & $n=59$ & \\
School & $70.34 \pm 19.7$ & $74.47 \pm 17.6$ & 0.09 \\
Emotion & $72.07 \pm 18.7$ & $72.20 \pm 20.4$ & 0.87 \\
Physical & $71.68 \pm 19.0$ & $74.15 \pm 19.7$ & 0.13 \\
Psychosocial & $71.84 \pm 15.5$ & $73.54 \pm 16.0$ & 0.36 \\
Social & $73.45 \pm 19.8$ & $74.07 \pm 18.7$ & 0.78 \\
Total score & $71.82 \pm 15.4$ & $73.79 \pm 15.0$ & 0.27 \\
Mother's report & $n=62$ & $n=62$ & \\
School & $68.24 \pm 18.9$ & $74.52 \pm 19.1$ & $<0.01$ \\
Emotion & $64.90 \pm 21.8$ & $67.81 \pm 20.3$ & 0.25 \\
Physical & $68.45 \pm 21.5$ & $73.64 \pm 20.6$ & 0.04 \\
Psychosocial & $67.85 \pm 17.4$ & $72.24 \pm 16.1$ & $<0.01$ \\
Social & $70.08 \pm 21.5$ & $74.62 \pm 17.6$ & 0.07 \\
Total score & $68.03 \pm 17.5$ & $72.62 \pm 16.0$ & $<0.001$ \\
Father's report & $n=34$ & $n=34$ & \\
School & $64.90 \pm 18.3$ & $71.77 \pm 17.7$ & 0.06 \\
Emotion & $68.68 \pm 23.2$ & $71.18 \pm 20.3$ & 0.46 \\
Physical & $68.47 \pm 23.7$ & $75.80 \pm 21.9$ & 0.09 \\
Psychosocial & $69.43 \pm 17.9$ & $71.69 \pm 17.8$ & 0.39 \\
Social & $73.24 \pm 21.2$ & $71.76 \pm 22.3$ & 0.68 \\
Total score & $69.48 \pm 18.1$ & $73.07 \pm 17.6$ & 0.19 \\
\hline a Completed for each pair. Values are & means \pm SD. & \\
\hline
\end{tabular}

\section{Discussion}

This prospective cohort study assessed the QoL of a cohort of 111 children who participated with their families in a nonselective INR self-monitoring education programme for VKA
Table 5 Comparison between both parents' reports for Qualin and PedsQL scores.

\begin{tabular}{llll}
\hline Dimension & $\begin{array}{l}\text { Mothers' } \\
\text { reports }^{\text {a }}\end{array}$ & $\begin{array}{l}\text { Fathers' } \\
\text { reports }^{\text {a }}\end{array}$ & $P$ \\
\hline Qualin & $n=9$ & $n=9$ & \\
Behaviour & $1.52 \pm 0.62$ & $1.42 \pm 0.50$ & 0.45 \\
Family environment & $1.65 \pm 0.32$ & $1.43 \pm 0.45$ & 0.13 \\
Ability to be alone & $0.11 \pm 0.32$ & $0.11 \pm 0.41$ & 0.98 \\
Sociability & $0.63 \pm 0.79$ & $0.69 \pm 0.78$ & 0.82 \\
Total score & $1.04 \pm 0.50$ & $0.99 \pm 0.49$ & 0.67 \\
PedsQL & $n=48$ & $n=48$ & \\
School & $66.20 \pm 19.8$ & $65.80 \pm 20.3$ & 0.83 \\
Emotion & $61.44 \pm 23.4$ & $64.70 \pm 22.9$ & 0.21 \\
Physical & $64.26 \pm 23.6$ & $64.98 \pm 24.7$ & 0.92 \\
Psychosocial & $65.66 \pm 19.3$ & $66.92 \pm 17.6$ & 0.40 \\
Social & $68.75 \pm 23.8$ & $69.97 \pm 20.7$ & 0.48 \\
Total score & $65.02 \pm 19.4$ & $66.11 \pm 18.5$ & 0.48 \\
\hline
\end{tabular}

a Completed at the same time and at first administration for each pair. Values are mean \pm SD.

treatment. QoL was good among children aged 1-4 years and was moderately impaired between 5 and 18 years of age. This non-selective education programme is dedicated to all children who require VKA therapy in our institution [17]. As opposed to previous studies, we did not select patients or families by their native language, type of VKA or adherence rate to INR testing [15].

Interestingly, the QoL in the youngest children was quite good. The "disability paradox" [24] might explain good QoL levels in adults with serious chronic diseases, as well as among teenagers or young adults with CHD $[2,25]$. A recent 
large-scale international study found that overall QoL in 4000 adults with CHD from 15 countries was generally good: indeed, Apers et al. suggested than variation in QoL was related to patient characteristics but not country-specific characteristics [26]. In our study, we can assume that the optimization of healthcare system might have directly benefited these young children and their parents in terms of QoL. That includes management of pain [27], reduction in duration of hospital stay with outpatient management even in critical conditions [28], availability of parent and child rooms at the hospital, full social security cover, childcare allowance, etc. The creation of a formalized VKA education programme is in line with this global care of young patients and their families. Similarly, recent studies suggested a better QoL for children entering a self-monitoring VKA programme $[15,16]$.

QoL among children older than 5 years, as reported by the children themselves or by their parents, was significantly lower than that of controls. However, long-term VKA treatment, as opposed to temporary treatment, did not impact the children's QoL in our study. Besides, QoL did not seem to be affected by the duration of the disease. Indeed, several mechanisms interfere with the severity and the duration of the chronic disease and therefore may act together or in opposition to determine QoL. For instance, in our cohort, the subgroup of children with CHD had lower QoL scores compared with children receiving VKA for another reason. These children were born with a congenital disease, underwent open-heart surgery, probably experienced some degree of physical limitation, and while growing up became progressively aware of their health condition. Therefore, added to long-term VKA therapy, the burden of the CHD certainly influenced their QoL. Because of this multifactorial effect on QoL status, we purposely chose generic QoL questionnaires in our VKA education programme, as opposed to studies using specific instruments dedicated to QoL in anticoagulation [29].

In our study, the QoL scores evaluated by the children and their fathers remained stable throughout the education programme whereas QoL scores evaluated by mothers increased during the programme, independently of any improvement in the cardiac condition. Mothers represent the largest sample of completed QoL questionnaires. In a recent study, we found that the actual physical impairment (peak oxygen uptake) of children with a CHD was better correlated with parent-reported QoL than with self-reported QoL [30]. Similarly, in the study from Jones et al., parents reported a significant improvement in PedsQL scores (mean increase: 11.1) of 35 children commencing home INR self-testing, whereas the children themselves did not [16]. In our study, no significant differences were observed between both parents when participating together in the same education session. The fathers who participated in the education sessions might have been particularly involved in their child's health condition and were therefore more accurate (vs fathers who did not participate) in their QoL reports. Therefore, parents' reports are essential in paediatric QoL studies and are usually required in paediatric clinical trials.

At the end of the programme, QoL as reported by mothers was significantly better for children under warfarin than for those under fluindione. Warfarin has the longest half-life of 36 to 42 hours and is usually recommended in paediatrics, supposedly for a better INR stabilization [31,32]. This QoL impairment in the fluindione group might reflect the impact of numerous INR adjustments and the burden of frequent blood monitoring on children.

\section{Study limitations}

Children with laboratory INR monitoring were not included, which represents a selection bias; indeed, all our patients participated in the INR self-monitoring programme and we no longer have such patients in our centre. Patients, families, specialist nurses and physicians request INR selfmonitoring, therefore we could not randomize our VKA population into two groups (self-monitoring versus laboratory) for ethical reasons. We cannot draw any conclusion from the QoL impairment in the youngest group of our study ( $<1$ year of age), as a small number of parents of children of that age participated in the education programme. QoL questionnaires and scorings were heterogeneous; as a result, some children switched from an instrument (Qualin) to another (PedsQL) between baseline and final sessions. Our control population was heterogeneous, was not contemporary for the infants [18], and was derived from a foreign culture for children aged 2 to 7 years [19]. We plan to achieve the constitution of a large contemporary control paediatric population for further QoL studies. Families participating in formalized education programs might represent a selected "privileged" population. This might explain why fathers' and mothers' QoL scores were so close. However, our education programme is non-selective, suggesting limited bias [17].

\section{Conclusions}

This prospective study provided original data about the QoL of a cohort of 111 children and their parents who were participating in a formalized INR self-monitoring education programme for VKA treatment. QoL scores were good among children $<4$ years of age, and were moderately impaired for children aged 5 to 18 years. Child-reported QoL was higher than the proxy values reported by their parents. Paternal and maternal proxy reports were similar, globally and for each dimension. QoL among the subgroup of children with CHD under VKA was the most impaired, and probably requires specific education programmes in addition to an INR self-monitoring programme. QoL scores increased during the education programme according to maternal reports only and independently of any improvement in the health condition.

\section{Acknowledgments}

This work was supported by grants from the ARCFA Association (Association pour la Recherche en Cardiologie du Fœtus à l'Adulte). We thank the families for their participation and Aurelie Grazioli, Maladon Traore and Virginie Salle for their excellent technical assistance. Medical writing assistance was provided by Valerie Macioce. 


\section{Disclosure of interest}

The authors declare that they have no competing interest.

\section{References}

[1] Anker SD, Agewall S, Borggrefe M, Calvert M, Jaime Caro $J$, Cowie MR, et al. The importance of patient-reported outcomes: a call for their comprehensive integration in cardiovascular clinical trials. Eur Heart J 2014;35:2001-9.

[2] Amedro P, Dorka R, Moniotte S, Guillaumont S, Fraisse A, Kreitmann B, et al. Quality of life of children with congenital heart diseases: a multicenter controlled cross-sectional study. Pediatr Cardiol 2015;36:1588-601.

[3] Moons P, Budts W, De Geest S. Critique on the conceptualisation of quality of life: a review and evaluation of different conceptual approaches. Int J Nurs Stud 2006;43:891-901.

[4] Bullinger M, Schmidt S, Petersen C, Erhart M, Ravens-Sieberer U. [Methodological challenges and potentials of health-related quality of life evaluation in children with chronic health conditions under medical health care]. Med Klin (Munich) 2007;102:734-45.

[5] Bauman ME, Black KL, Massicotte MP, Bauman ML, Kuhle $S$, Howlett-Clyne S, et al. Accuracy of the CoaguChek XS for point-of-care international normalized ratio (INR) measurement in children requiring warfarin. Thromb Haemost 2008;99:1097-103.

[6] Marzinotto V, Monagle P, Chan A, Adams M, Massicotte P, Leaker $M$, et al. Capillary whole blood monitoring of oral anticoagulants in children in outpatient clinics and the home setting. Pediatr Cardiol 2000;21:347-52.

[7] Newall F, Monagle P, Johnston L, Home INR. monitoring of oral anticoagulant therapy in children using the CoaguChek S pointof-care monitor and a robust education program. Thromb Res 2006;118:587-93.

[8] Sawicki PT. A structured teaching and self-management program for patients receiving oral anticoagulation: a randomized controlled trial. Working Group for the Study of Patient SelfManagement of Oral Anticoagulation. JAMA 1999;281:145-50.

[9] Cromheecke ME, Levi M, Colly LP, de Mol BJ, Prins MH, Hutten $B A$, et al. Oral anticoagulation self-management and management by a specialist anticoagulation clinic: a randomised cross-over comparison. Lancet 2000;356:97-102.

[10] Kulinna W, Ney D, Wenzel T, Heene DL, Harenberg J. The effect of self-monitoring the INR on quality of anticoagulation and quality of life. Semin Thromb Hemost 1999;25:123-6.

[11] Fitzmaurice DA, Murray ET, Gee KM, Allan TF, Hobbs FD. A randomised controlled trial of patient self management of oral anticoagulation treatment compared with primary care management. J Clin Pathol 2002;55:845-9.

[12] Jowett S, Bryan S, Murray E, McCahon D, Raftery J, Hobbs FD, et al. Patient self-management of anticoagulation therapy: a trial-based cost-effectiveness analysis. $\mathrm{Br} \mathrm{J}$ Haematol 2006;134:632-9.

[13] Khan TI, Kamali F, Kesteven P, Avery P, Wynne H. The value of education and self-monitoring in the management of warfarin therapy in older patients with unstable control of anticoagulation. Br J Haematol 2004;126:557-64.
[14] Voller H, Taborski U, Dovifat C, Hartwig I, Kadar JG, Wegscheider $\mathrm{K}$, et al. ProTime self-management yielding improvement of fluency and quality of life. Thromb Haemost 2007;98:889-95.

[15] Bauman ME, Massicotte MP, Kuhle S, Siddons S, Bruce AA. EMPoWARed: Edmonton pediatric warfarin self-management study. Thromb Res 2015;136:887-93.

[16] Jones S, Monagle P, Manias E, Bruce AA, Newall F. Quality of life assessment in children commencing home INR self-testing. Thromb Res 2013;132:37-43.

[17] Bajolle F, Lasne D, Elie C, Cheurfi R, Grazioli A, Traore M, et al. Home point-of-care international normalised ratio monitoring sustained by a non-selective educational program in children. Thromb Haemost 2012;108:710-8.

[18] Manificat S, Dazord A, Langue J, Danjou G, Bauche P, Bovet F, et al. [Evaluation of the quality of life of infants and very young children: validation of a questionnaire. Multicenter European study]. Arch Pediatr 2000;7:605-14.

[19] Varni JW, Seid M, Kurtin PS. PedsQL 4.0: reliability and validity of the Pediatric Quality of Life Inventory version 4.0 generic core scales in healthy and patient populations. Med Care 2001;39:800-12.

[20] Teissier S, Lemelle VA, J.L.. Appl Psychol 2009;59:291-300.

[21] Guillemin F, Bombardier C, Beaton D. Cross-cultural adaptation of health-related quality of life measures: literature review and proposed guidelines. J Clin Epidemiol 1993;46:1417-32.

[22] Tessier S, Vuillemin A, Lemelle J-L, Briancon S. Psychometric properties of the French Pediatric Quality of Life Inventory Version 4.0 (PedsQL ${ }^{T M}$ 4.0) generic core scales. Eur Rev Appl Psychol 2009;59:291-300.

[23] Uzark K, Jones K, Slusher J, Limbers CA, Burwinkle TM, Varni JW. Quality of life in children with heart disease as perceived by children and parents. Pediatrics 2008;121:e1060-7.

[24] Moons P, Norekval TM. Is sense of coherence a pathway for improving the quality of life of patients who grow up with chronic diseases? A hypothesis. Eur J Cardiovasc Nurs 2006;5:16-20.

[25] Utens EM, Bieman HJ, Verhulst FC, Meijboom FJ, Erdman RA, Hess J. Psychopathology in young adults with congenital heart disease. Follow-up results. Eur Heart J 1998;19:647-51.

[26] Apers S, Kovacs AH, Luyckx K, Thomet C, Budts W, Enomoto J, et al. Quality of life of adults with congenital heart disease in 15 countries: evaluating country-specific characteristics. J Am Coll Cardiol 2016;67:2237-45.

[27] Rabbitts JA, Palermo TM, Zhou C, Mangione-Smith R. Pain and health-related quality of life after pediatric inpatient surgery. J Pain 2015;16:1334-41.

[28] Schweiger M, Vanderpluym C, Jeewa A, Canter CE, Jansz P, Parrino PE, et al. Outpatient management of intra-corporeal left ventricular assist device system in children: a multi-center experience. Am J Transplant 2015;15:453-60.

[29] Bruce AA, Bauman ME, Black K, Newton A, Legge L, Massicotte MP. Development and preliminary evaluation of the KIDCLOT PAC QL: a new health-related quality of life measure for pediatric long-term anticoagulation therapy. Thromb Res 2010;126:e116-21.

[30] Amedro P, Picot MC, Moniotte S, Dorka R, Bertet H, Guillaumont $\mathrm{S}$, et al. Correlation between cardio-pulmonary exercise test variables and health-related quality of life among children with congenital heart diseases. Int J Cardiol 2016;203:1052-60.

[31] Monagle P, Chan AK, Goldenberg NA, Ichord RN, Journeycake JM, Nowak-Gottl U, et al. Antithrombotic therapy in neonates and children: antithrombotic therapy and prevention of thrombosis, 9th ed: American college of chest physicians evidence-based clinical practice guidelines. Chest 2012;141:e737S-801S.

[32] Law C, Raffini L. A guide to the use of anticoagulant drugs in children. Paediatr Drugs 2015;17:105-14. 